\title{
Arg-C, Asp-N Protein Cleavage Reagent
}

National Cancer Institute

\section{Source}

National Cancer Institute. Arg-C, Asp-N Protein Cleavage Reagent. NCI Thesaurus. Code C161879.

A protein cleavage reagent comprised of a mixture of the bacterial endopeptidases Arg$\mathrm{C}$ and Asp- $\mathrm{N}$ that cleaves proteins into peptides at the $\mathrm{C}$-terminal side of a lysine or arginine residue and the $\mathrm{N}$-terminal side of an aspartate residue. 